\title{
ORGANEROS, MÚSICOS Y EMPRESARIOS: LA FAMILIA DE- BERNARDI EN SALAMANCA ENTRE 1903 Y 1932.
}

\author{
ORGAN BUILDERS, MUSICIANS AND ENTREPRENEURS: \\ THE DE- BERNARDIS FAMILY IN SALAMANCA, 1903-1932.
}

\author{
Judith Helvia García Martín \\ Universidad de Salamanca \\ helvia@usal.es \\ ORCID iD: https://orcid.org/0000-0001-5775-3925
}

\begin{abstract}
Resumen
A principios del siglo XX, Salamanca acogió a la que sería una de las familias cultural y musicalmente más activas de dicha ciudad durante las tres primeras décadas de la centuria: los DeBernardi. Sus actividades como organeros, músicos, profesores y empresarios de la música, centradas en las figuras de Juan De- Bernardi y su hijo Luis, dejaron huella no solo en la ciudad mediante su participación en numerosos eventos culturales, sino también a través de la construcción y reparación de varios instrumentos en un área que abarca desde el norte de Portugal hasta el sur de Cáceres. Aquí reconstruimos, a través de la información contenida en fuentes hemerográficas locales, su trayectoria desde su llegada a Salamanca en 1903 hasta 1932.

\section{Palabras clave}

Juan De- Bernardi, Luis De- Bernardi, órgano, Salamanca, actividad musical, siglo $\mathrm{XX}$, prensa.
\end{abstract}

\section{JUAN DE- BERNARDI: UN INVITADO INESPERADO ${ }^{1}$}

En el año 2013 tuve la oportunidad de llevar a cabo una investigación con motivo de la realización del trabajo de

1 Quiero manifestar aquí mis agradecimientos por la ayuda prestada para esta investigación a varias personas que, generosamente, me han cedido información: a Luis Dalda Gerona, director del trabajo de investigación que dio lugar a este artículo; a Federico Acitores, que aportó su experiencia como organero; a Pilar y Silvia De- Bernardi, descendientes directas de la familia y que han actuado como informantes; y a José María Hernández Pérez.

\begin{abstract}
In the early 20th century, Salamanca hosted one of the most culturally and musically active families of the city during the first three decades of the century: the De- Bernardis. Their activities as organ builders, musicians, teachers and music entrepreneurs, focused on the figures of Juan De- Bernardi and his son Luis, left a mark not only in the town, through their involvement in numerous cultural events, but also building and reparing various instruments in an area that covers from the North of Portugal to the South of Cáceres. Here we reconstruct, through the information given by local hemerographic sources, their trajectory from their arrival in Salamanca in 1903 until 1932.
\end{abstract}

\section{Key words}

Juan De- Bernardi, Luis De- Bernardi, pipe organ, Salamanca, musical activity, 20th Century, press.

fin de carrera encaminado a la obtención del Grado Superior de Música ${ }^{2}$. Dicho estudio se orientó hacia la búsqueda de fuentes relacionadas con la construcción del órgano ubicado en la iglesia parroquial de la Purísima Concepción, en la ciudad de Salamanca. Este instrumento, pese a ser una interesante creación de Aquilino Amezua que data de 1902, permanecía en silencio y necesitado de reparación desde hacía varias décadas. Por lo tanto, cifré mi atención en recabar

2 La mayor parte de los resultados de dicho estudio pueden leerse en: GARCÍA MARTÍN, 31 (Zaragoza, 2016): 149-184. 
toda la información posible que, a la postre, permitiera poder realizar un proyecto de restauración que fuera factible a corto- medio plazo y, así, rehabilitar cuanto antes el instrumento e insertarlo de nuevo en la vida musical salmantina ${ }^{3}$.

Las actas recogidas en la parroquia donde se ubica este órgano señalan que el instrumento fue objeto de una importante restauración en 1920 ya que, según la prensa de la épo$\mathrm{ca}^{4}$, "permanecía silencioso debido a ciertos desperfectos que el tiempo y el uso habían producido en su factura" . Su restaurador había sido un tal Juan De- Bernardi quien, según las crónicas que relataban los conciertos de reinauguración de dicho órgano, era un personaje de cierta relevancia en el panorama musical salmantino. Y como aún habría de encontrarme con él repetidas veces en el proceso de investigación del instrumento en cuestión, consideré que su figura y trayectoria profesional merecían un estudio aparte, sin sospechar todavía la popularidad que en la zona occidental de la Península Ibérica habían alcanzado el citado señor De- Bernardi y su familia.

Los datos biográficos acerca de esta familia no abundan. Felipe Pedrell cita en la voz "Orquestadeón" de su Diccionario técnico de la música al inventor artífice de este instrumento, el "organero italiano establecido en Trujillo Nicolás Bernardi". Así mismo, el cronista José Antonio Ramos Rubio ha desgranado alguna información sobre la actividad de esta familia en Extremadura a lo largo de varios artículos ${ }^{7}$. Según este autor, el organero Nicolás De- Bernardi y su mujer, Jerónima Boccino, llegaron a España para cumplir con algún encargo realizado por el obispo de Zamora, tras lo cual se instalan en Trujillo. Estos datos no han podido ser contrastados con fuentes. Lo que

3 Mediante esta investigación se pudo generar transferencia de conocimiento, ya que en el verano de 2013 el organero Federico Acitores realizó una intervención en el órgano que permitió su puesta en funcionamiento para volver a dar conciertos en él. GARCÍA MARTÍN, 9 (Madrid, 2016): 31-52.

4 Todas las referencias de prensa han sido extraídas de las digitalizaciones realizadas en la Biblioteca Virtual de Prensa Histórica de los periódicos locales salmantinos El Lábaro (digitalizado: 1897-1910) y El Adelanto (digitalizado: 1883-1932), cuyos enlaces facilitamos a continuación. Por lo tanto, en lo sucesivo, tan sólo citaremos en cada caso el periódico y la fecha en la que se encuentran las noticias (en su mayoría, notas de prensa y reseñas sin firmar, por lo que no resulta posible rastrear las relaciones entre quien escribe y el objeto de la reseña), siendo estos documentos de fácil localización: acudiendo a las bases de datos digitalizadas y buscando los artículos por fecha, se puede encontrar el objeto de interés gracias a la digitalización con OCR de los archivos. http://prensahistorica.mcu.es/es/consulta/registro.cmd?id=9500 (Consultado el 25 de febrero de 2017).

http://prensahistorica.mcu.es/es/consulta/registro.cmd?id=7188

(Consultado el 25 de febrero de 2017).

5 El Adelanto. 25 de junio de 1920.

6 PEDRELL (1897): 529.

7 RAMOS RUBIO, 20 (Sevilla, 2006): 223-229. RAMOS RUBIO y GUTIÉRREZ MARCOS, 24 (Sevilla, 2010): 363-382. sí parece cierto, como rezan los carteles encolados en varios instrumentos de la zona ${ }^{8}$, es que "Nicolás De- Bernardi e hijos, organeros italianos" realizaron varios encargos de restauración de órganos en Extremadura durante la última década del siglo XIX hasta que, en 1899, Nicolás muere y sus hijos se independizan del taller paterno. Uno de ellos, Juan, se afinca al poco tiempo en Salamanca, donde permanecería hasta su muerte en los años 40 , según informantes de la familia. La proximidad cronológica de este personaje con el presente ha facilitado que se pudiera contactar con descendientes directas (concretamente una nieta y una bisnieta), cuya ayuda ha resultado inestimable a la hora de esclarecer el árbol genealógico de los De- Bernardi una vez establecidos en Salamanca (figura 1).

Como veremos a continuación, Juan De- Bernardi llegó a la ciudad en 1903, casado con María Romero (figura 2) a la que probablemente había conocido durante su estancia en Extremadura. Una vez instalado, su familia crecería y su actividad evolucionaría significativamente, desde la regencia de una tienda de pianos y armonios, pasando por la organería, la docencia de la música e incluso la composición, llegando a ser un empresario conocido y respetado ${ }^{10}$ en la ciudad, que alternaba en las veladas culturales con personajes de la talla de Gerardo Gombau o Bernardo García- Bernalt ${ }^{11}$. Sin embargo, del casi medio siglo que vivió en Salamanca, aquí sólo hablaremos del período comprendido entre 1903, momento en el que llega a la ciudad, y 1932. Los motivos que nos obligan a detenernos en esta fecha son dos: por un lado, la digitalización de la prensa local (El Lábaro y El Adelanto ${ }^{12}$ ) que nos proporciona noticias sobre la actividad de esta familia llega hasta 1932; por otra parte, a partir 1930 las referencias a la familia De- Bernardi en las fuentes hemerográficas disminuyen significativamente. Los motivos de esta merma en las noticias sobre nuestros protagonistas pueden deberse a la dispersión de los hijos una vez casados y a una menor actividad del propio Juan De- Bernardi que, a partir de cierto momento, deja de intervenir en los órganos de Salamanca y alrededores para buscar la comodidad de su tienda en la capital.

8 Podemos encontrar imágenes de estos carteles en los artículos de José Antonio Ramos Rubio citados anteriormente.

9 Hija de Bruno Romero, muerto en 1909 (El Adelanto, 13 de enero de 1909). La fotografía de la figura 2 ha sido amablemente cedida por una nieta de Juan De- Bernardi.

10 El Adelanto se encarga de felicitarle por su santo durante varios años llegando los días 22, 23 o 24 de junio $(1912,1914,1915,1920$, $1923,1925,1926,1927,1928,19291930$ у 1932).

11 En 1913 acude a un concierto- homenaje a Tomás Bretón, en el que coincide con personalidades del panorama cultural salmantino como Miguel de Unamuno, Miguel Íscar Peyra, Dámaso Ledesma o el propio Tomás Bretón (El Adelanto, 25 de mayo de 1913).

12 Aunque existen otros periódicos en esta época, su publicación es de ámbito cronológico más reducido y periodicidad irregular. 
Por todo lo comentado hasta el momento, a lo largo de este artículo desgranaremos las noticias que nos han llegado a través de la prensa ${ }^{13}$ e informantes de los De- Bernardi en sus diferentes facetas como empresarios, organeros, músicos y profesores. A pesar del carácter local que pueda aparentar tener este estudio, no podemos dejar de caer en la cuenta de que va más allá de la mera reconstrucción biográfica de un organero y su hijo músico. Se trata también de una crónica de la evolución de los negocios musicales durante la primera mitad del siglo XX, trayectoria que podemos seguir a través de los cambios en una empresa familiar. Pero además es un relato sobre el día a día musical y el modo de vida de una familia burguesa en una ciudad de provincias, que era participante activa y pasiva en la vida cultural de la misma (relataremos qué tipo de reuniones frecuentaban, a qué instituciones y asociaciones musicales acostumbraban abonarse...).

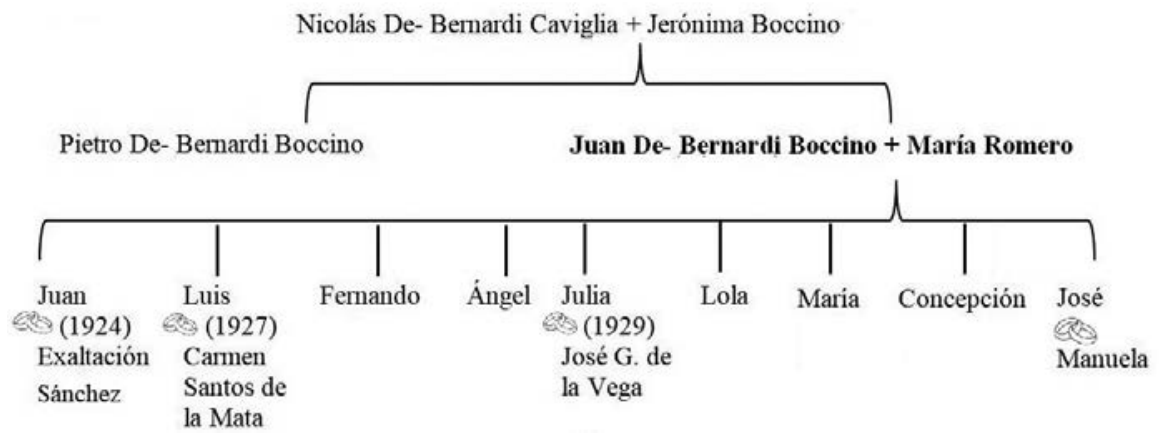

Fig. 1. Reconstrucción del árbol genealógico de los De- Bernardi ${ }^{14}$

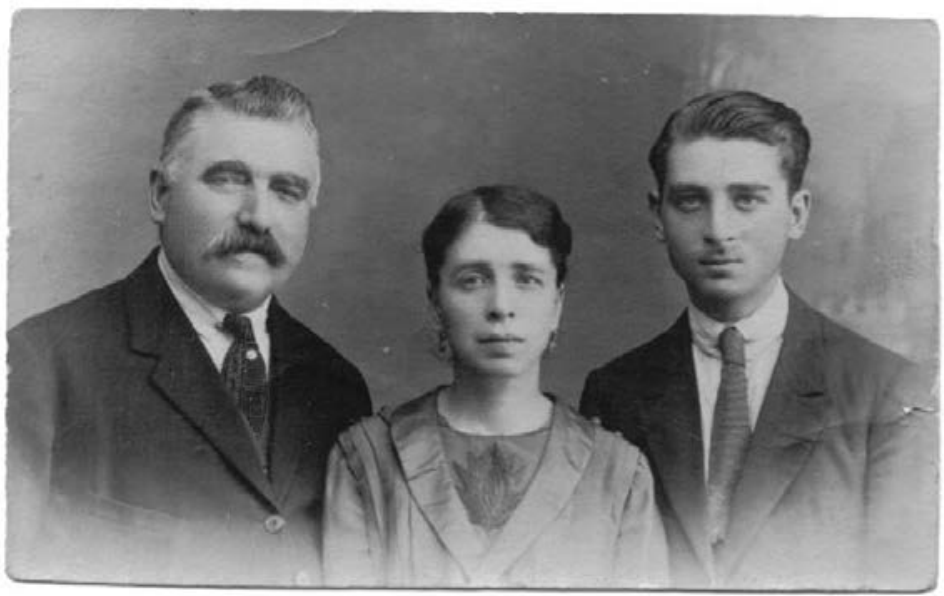

Fig. 2. Juan De- Bernardi, María Romero y uno de sus hijos mayores.

13 Aunque la cantidad de referencias encontradas en la prensa es significativa (254 noticias y 827 anuncios publicitando el negocio familiar), no podemos dejar de hacer notar que su registro ha sido realizado mediante un vaciado facilitado por el OCR, un recurso que, si bien es sumamente útil, no es infalible, debido al deterioro tipográfico en algunos de los periódicos, que dificulta el reconocimiento de caracteres. Por lo tanto, dejamos constancia de la posibilidad de que hayan quedado noticias sin señalar. Por otro lado, debo aclarar que este artículo ha sido redactado procurando que el cuerpo del texto no resulte demasiado prolijo en fechas ni anécdotas que hicieran de su lectura algo tedioso, dejando estos datos para las notas a pie de página, a fin de que puedan satisfacer al lector más curioso. Por último, es necesario recordar que los datos indicados en estas notas corresponden a las fechas en que las noticias aparecen en los periódicos, que pueden no coincidir con el día concreto en el que tiene lugar el acontecimiento reseñado.
14 El árbol genealógico ha podido ser reconstruido gracias, por una parte, a las noticias de prensa y, por otra, a una de las descendientes de Juan De- Bernardi, que también ha cedido amablemente la fotografía de la figura 2. 


\section{JUAN DE- BERNARDI, EMPRESARIO. SALAMANCA: UN MERCADO MUSICAL POR CONQUISTAR}

Como hemos señalado, los periódicos locales El Lábaro y El Adelanto recogen, durante los primeros treinta años del siglo, numerosos indicios de las diferentes actividades y vida social de la familia protagonista de este artículo. Pero el elemento que nos ilustra cómo evolucionó la empresa familiar es la publicidad que Juan De- Bernardi pagaba regularmente para promocionar su tienda de pianos y armonios. A través de ella, podemos percibir una suerte de relación quid pro quo, en la que De- Bernardi paga anuncios ${ }^{15}$ sobre su negocio durante años, y los periódicos ofrecen constantes notas sobre su actividad profesional, social e incluso la de sus hijos, y sobre lo satisfechos que quedan todos sus clientes. En un principio es El Lábaro el que más información aporta, pero una vez este desaparece en 1910, será El Adelanto el que tome el relevo hasta $1932^{16}$.

Gracias también a estos reclamos, sabemos que trasladó su negocio varias veces hasta encontrar un lugar en el que estuviera conforme, pero siempre ubicándolo en locales céntricos y en zonas comerciales, probablemente con un alquiler costoso. Empezó en el número 51 de la calle Zamora en 1903, cambiando dos veces de número en la misma calle: al $28^{17}$ en 1904 y al 35 en $1914^{18}$, para asentarse final y definitivamente en el número 5 de la que entonces era la calle Pérez Pujol (hoy Calle Concejo) a partir de 1920, aunque ya desde el año anterior los periódicos dan cuenta de los trámites para las obras ${ }^{19}$.

Como vemos en la figura $3^{20}$, viene desde Zamora para comenzar su andadura en Salamanca de forma discreta a finales de noviembre de 1903, indicando en los mensajes una estancia pasajera de 15 días para reparar pianos y armonios. Evidentemente se trataba de un viaje orientado a tantear el

15 A modo ilustrativo, en este apartado incluiremos algunos de estos anuncios que, por motivos de contenido, sean importantes. Sin embargo, para no saturar de imágenes este artículo, el resto ha sido transcrito o resumido su contenido. A la hora de hacer las transcripciones, se ha normalizado la ortografía (incluyendo los nombres de autores, compositores, constructores de instrumentos...). Con el objeto de conservar la intención de reclamo de estos anuncios, se han conservado las palabras escritas con mayúsculas, las negritas y cursivas.

16 Última fecha digitalizada de este diario en la plataforma ya citada en la fecha de entrega de este artículo.

17 El Adelanto, 29 de octubre de 1904.

18 El adelanto, 1 de mayo de 1914.

19 El 31 de julio de 1919 le conceden la licencia de obras, y el 11 de octubre del mismo año se aprueba la delineación de la finca que ocuparía su local (en El Adelanto).

20 El Lábaro. 21 de noviembre de 1903. mercado potencial en la capital, ya que apenas pasado dicho plazo su estadía se acabaría convirtiendo en permanente, estableciéndose en la que hoy es una de las principales calles comerciales de la ciudad. En el anuncio de la figura $4^{21}$ observamos que se ofrece no solo a reparar órganos de iglesia, pianos y armonios, sino también a construirlos, lo que indica un taller ya establecido con todos los recursos.

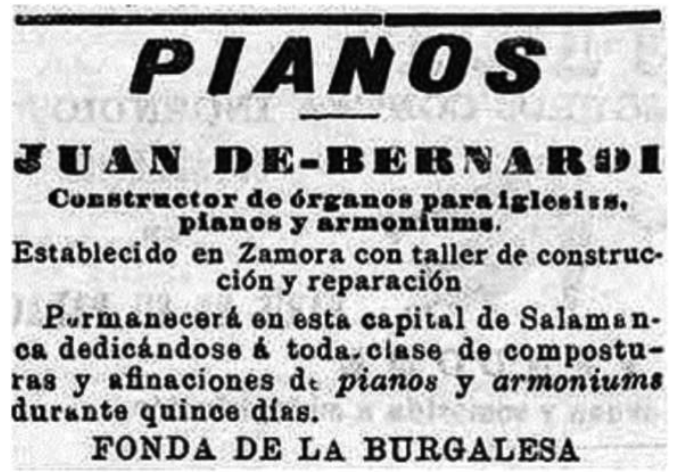

Fig. 3. Anuncio. 1903

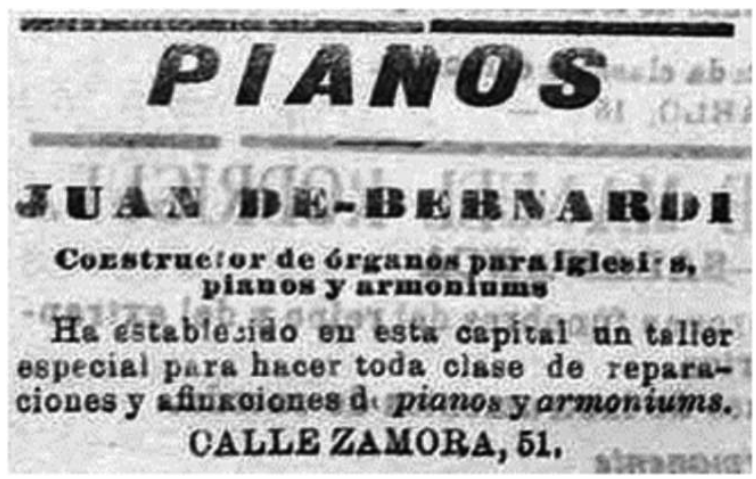

Fig. 4. Anuncio. 1903

Pocos meses más tarde puede permitirse una publicidad con mucha más información, en un anuncio que refleja el gusto de aquel momento heredado de la organería romántica francesa por dotar al órgano de registros que imitasen timbres orquestales, así como la costumbre de los organeros de la época de insertar en órganos barrocos registros propios del órgano romántico como la voz humana, seguramente a la francesa ${ }^{22}$ :

21 El Lábaro. 14 de diciembre de 1903.

22 Aunque las referencias a la "voz humana" se vienen dando en la organería ibérica desde el siglo XVI entendemos que, en este caso, por la fecha, el contexto y las intervenciones de De- Bernardi en otros 
Órganos. Juan De- Bernardi. Constructor y reparador de órganos de iglesia, pianos y armóniums, ya establecido en esta ciudad.

Se construyen órganos de tubería para catedrales, parroquias y conventos, con toda clase de registros que se puedan desear y con imitaciones de todos los instrumentos de orquesta, banda y especialidad en voces humanas, pudiéndose aplicar estos registros en cualquiera órgano antiguo a precio módico.

Pídanse precios de órganos pues se hacen desde 2100 pesetas en adelante, con ocho registros y de sólida construcción.

Taller para toda clase de composturas y afinaciones de pianos, armóniums y órganos.

CALLE DE ZAMORA, 51. SALAMANCA ${ }^{23}$.

Por otro lado, llama la atención que en los dos primeros anuncios ofrezca sus servicios como vendedor y reparador de pianos, palabras que aparecen bien visibles en el reclamo; y sin embargo, en este último, publicado a lo largo de los años 1904 y 1905, resalta su labor de constructor. Esto puede mostrar bien una especialización voluntaria por parte del organero, o bien el reflejo de una demanda real en el mercado del momento ${ }^{24}$.

A partir de 1908 y durante dos años, los anuncios se hacen cada vez más sobrios, en los que vemos una subida de su caché junto con el precio de los órganos que publicita ("desde 4000 pesetas" ${ }^{25}$ ), en los que resalta especialmente registros "flautados, trompetería y voces humanas". Pero poco a poco a partir de 1910 , y aunque va a seguir ejerciendo de organero hasta 1920, su tienda va a promocionar cada vez

órganos, que lo que él añadía eran voces humanas "a la francesa", de sonido y timbre más suaves. SAURA BUIL (2001): 501.

23 El Lábaro. 2 de abril de 1904.

24 Estamos en los años inmediatamente posteriores al Motu Proprio de Pío X, que en España había dado lugar a una serie de congresos que buscaban regular las prácticas musicales en la iglesia. En lo tocante a instrumentos como el órgano el Motu Proprio es claro, señalando que es el único instrumento permitido (y no siempre). En el congreso de Valladolid de 1907 se indica la necesidad de "unificar el arte organístico español, recomendando no reconstruir órganos y, en caso de hacerlo, tener cuidado de ampliar los juegos de fondo, aunque se preferían los órganos nuevos, y en caso de problemas económicos, sustituirlo por el armonio. En ese sentido, se ponía sobre aviso a los párrocos acerca de los organeros ambulantes que probablemente ofrecían sus servicios sin rigor ni calidad en busca de beneficios fáciles". AVIÑOA, 27-1 (Madrid, 2004): 388. Posiblemente De- Bernardi, al tanto de estos preceptos, recibiera numerosos encargos para intervenir en órganos que estuvieran deteriorados por el abandono tras más de un siglo de desamortizaciones, o bien realizara remodelaciones conforme a los nuevos gustos de la época. Y de hecho, los anuncios a partir de 1911 muestran cómo uno de los productos estrella que promociona son los armonios para parroquias. 25 El Lábaro. 23 de marzo de 1908. menos los órganos, y cada vez más una diversificación en los artículos musicales que vende. Ahora los anuncios relatan que vende no solo pianos, sino también armonios y música tanto escrita como en rollos de pianola, importando materiales desde Madrid, Barcelona e incluso Nueva York ${ }^{26}$.

Pianos. El señor De- Bernardi, en breve, abrirá en esta capital un almacén de pianos, armoniums y música de todas clases, religiosa, zarzuelas, bailables, estudios, etcétera, al mismo precio que se despacha en las casas editoriales.

Los pianos serán de las mejores marcas y con el 10 por 100 más baratos que en los almacenes de Madrid, garantizados contra todo defecto de construcción y averías que pueden ocurrir en el viaje. También se venderán pianos a plazos ${ }^{27}$.

Ya en su primer anuncio tras la nueva orientación del negocio en 1911, vemos claramente esa diversificación. Leemos en las siguientes transcripciones que ahora ya es un "Almacén de pianos y música", en el que se incluirán multitud de productos relacionados con la profesión. Se venden órganos, sí, pero también pianos que incluso pueden alquilarse; y se amplía la gama de instrumentos que ofrecen, así como otros accesorios y partituras. Sus anuncios se volverán más descriptivos y aumentará la cantidad de información en el año siguiente y en los sucesivos, indicando diversas facilidades de venta, así como las garantías de calidad por sus convenios con prestigiosas casas europeas como Erard, Pleyel o Ronisch, convirtiéndose así en un importante distribuidor de productos importados ${ }^{28}$.

\section{Almacén de pianos y música de Juan De Bernardi.}

Pianos negros y de color natural, de las mejores marcas, a precios reducidos y garantizados contra todo defecto de construcción. Además de los precios tan reducidos, esta casa se obliga a afinar los pianos que vende gratis una vez, y también se obliga a reparar gratis todos los desperfectos que ocurran durante cinco años. En breve se recibirán los tan renombrados pianos ERARD y PLEYEL, de París.

Alquileres y cambios. Armoniums de varias marcas. Órganos por encargo, para Catedrales, parroquias y conventos, desde 4.000 pesetas. Música religiosa y profana. Acordeones, violines, guitarras y bandurrias. Accesorios para toda clase de instrumentos. Afinaciones y reparaciones. Calle de Zamora, 28, Salamanca ${ }^{29}$.

26 El Adelanto, 13 de julio de 1917.

27 El Adelanto. 26 de agosto de 1911.

28 A estos acuerdos de importación llegó tal vez en el viaje de dos semanas que realizó con su familia a Madrid y Barcelona en los días previos a la apertura de su nuevo negocio (10 y 24 de agosto de 1911).

29 El Adelanto. 1 de noviembre de 1911. 


\section{Almacén de J. De-Bernardi.}

Pianos de las mejores marcas nacionales y extranjeras, a precios muy económicos y garantizados por cinco años. Pinos a manubrio. Armoniums de varias marcas de París. Órganos de tubería, por encargo.

Ventas al contado y a plazos. Cambios y alquileres.

Acordeones, violines, guitarras, bandurrias y demás clases de instrumentos y accesorios.

Música religiosa, zarzuelas bailables, métodos, etc., etc. Estudios para todos los cursos del Conservatorio.

Esta casa responde de la legitimidad y bondad de todos sus instrumentos.

El señor De Bernardi tiene establecidos convenios especiales con las fábricas de pianos Chassaigne Fréres, Erard, Pleyel, Phrynis, Ronisch, Ribalta, Vidal y otras varias; por lo que se explican las grandes ventajas que ofrece esta casa.

Los señores compradores pueden recibir los pianos y armoniums directamente de la fábrica, libre de portes y riesgos, si no les conviniera los del almacén. Calle de Zamora, 28, Salamanca ${ }^{30}$.

Durante los años siguientes y hasta 1921, Bernardi va a seguir esta trayectoria y línea de trabajo, manteniendo abiertas las dos tiendas de la Calle Zamora. De ellas hemos encontrado numerosos ejemplos de anuncios, a veces centrados en la sección pianística, otras en la organística, y a veces en aparatos de reproducción automática de música, como pianolas y autopianos ${ }^{31}$ :

MÚSICA de gran éxito: LA CANCIÓN DEL OLVIDO, EL NIÑO JUDÍO y LA LLAMA. Todos los números publicados para piano y pianola están de venta en el Almacén de Música de J. De Bernardi, Salamanca.

Pianos y pianolas de las mejores marcas nacionales y extranjeras, a precios sin competencia. Pianos de ocasión, cambios y alquileres. Esta casa garantiza todos los pianos que vende ${ }^{32}$.

Ya en 1920 el negocio cambia de lugar a la antigua calle Pérez Pujol, pero mantiene el enfoque diversificado del mismo. A lo largo de esta década, además de ofrecer la habitual venta de instrumentos, partituras y rollos de pianola, va a incorporar formatos sonoros más modernos, como pianos

30 El Adelanto. 19 de junio de 1912. de 1915 .

31 El Adelanto, 1 de julio de 1914, 1 de febrero y 24 de agosto

32 El Adelanto. 2 de mayo de 1918 eléctricos para bares, gramófonos y discos (a veces especificando las marcas, como La voz de su amo, Odeón, Decca y Regal), pianos de manubrio marca Casali y pianolas marca Aeolian y Wridner ${ }^{33}$.

\section{¡GRAN REBAJA!}

La casa De- Bernardi ha puesto a la venta más de 200 couplets de actualidad, con una rebaja del 25 por 100 , y otros tantos de varias ediciones, con la rebaja del 40 por 100. Surtido en rollos para pianolas, marcas "Victoria" y “Armonie". Pérez Pujol, 5 y $7^{34}$.

Pianos. La casa De- Bernardi es la que da más garantías y vende más barato que las de Madrid los pianos, pianolas, etc. De las marcas más selectas. Piezas de música de todas las clases y estudios. Pianos de manubrio, acordeones, violines, guitarras, etc. Reparaciones y afinaciones, cambios y alquileres ${ }^{35}$.

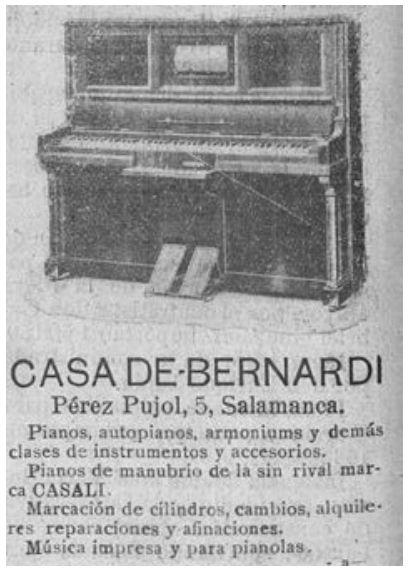

Fig. 5. El Adelanto 18 de abril de 1926

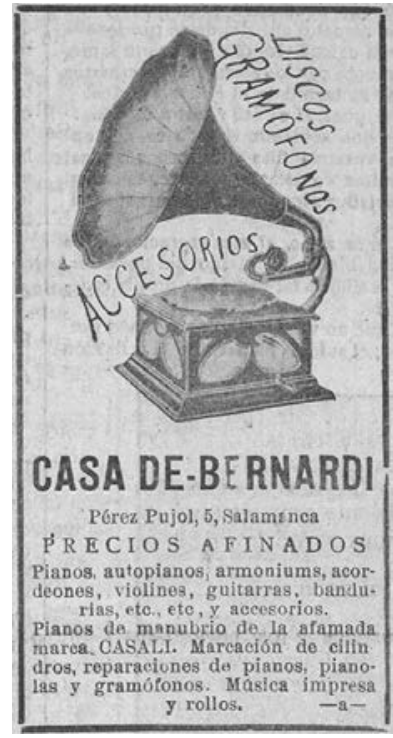

Fig. 6. El Adelanto

7 de octubre de 1924
33 El Adelanto, respectivamente: 7 de febrero de 1923; 8 de julio de 1925 y 20 de febrero de 1930; 29 de marzo de 1928 y 16 de febrero de 1929.

34 El Adelanto. 28 de abril de 1921

35 El Adelanto, 8 de agosto de 1922 


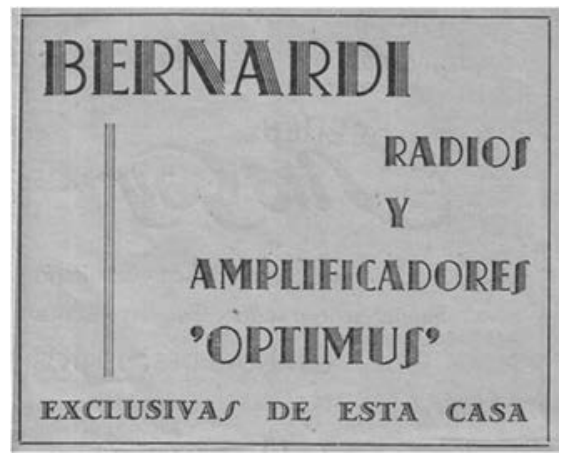

Fig. 7. Contraportada de programa de mano de un concierto en 1945

Aunque 1932 sea el último año de prensa digitalizada, y por lo tanto lo hayamos establecido como límite temporal, no queremos terminar ese apartado sobre la evolución de un negocio musical en la primera mitad del siglo XX sin una última pista encontrada en la contraportada de un programa de mano de un concierto ofrecido por la Orquesta Sinfónica de Salamanca el 21 de febrero de $1945^{36}$. En el espacio cedido para publicidad en dicho documento encontramos este anuncio, en el que observamos cómo el negocio familiar se había adaptado a los nuevos tiempos, transformando el inicial taller familiar de organería y reparación de pianos, en una tienda moderna distribuidora de las últimas tecnologías.

A toda esta actividad propagandística del negocio familiar, hay que sumarle varias referencias en prensa que muestran que Juan De- Bernardi era un empresario comprometido y reconocido por su entorno ${ }^{37}$. Por una parte, $E l$ Adelanto da fe de varios de sus viajes sin especificar que tuvieran que ver con la reparación de órganos, por lo que probablemente tenían fines empresariales, a lugares cercanos como Cáceres, Zamora, Ciudad Rodrigo o Peñaran$\mathrm{da}^{38}$. Por otro lado, su presencia en la comunidad local de comerciantes era destacada, pues varias veces se señala su asistencia a las reuniones de la Cámara de Comercio y la Patronal de Comerciantes ${ }^{39}$. En tercer lugar, De- Bernardi y

36 GEJO SANTOS (2015): 388 y 735. Informante: Petra Ferrer. 37 En ocasiones la prensa reseña que los instrumentos utilizados en diversos eventos culturales se compraron en la casa de De- Bernardi (El Adelanto, 7 de diciembre de 1912; 22 de abril de 1922). Otra anécdota cuenta cómo, tras el descarrilamiento de un tren, llaman a Juan De- Bernardi como perito para que tase los daños sufridos por los instrumentos musicales en el accidente (El Adelanto, 18 de marzo de 1928).

38 En El Adelanto. A Cáceres: 7 de agosto de 1906 y 3 de junio de 1907. A Zamora: 13 de agosto de 1908, 5 de febrero de 1919 y 11 de octubre de 1919. A Ciudad Rodrigo: 12 de febrero de 1921 y 25 de abril de 1923. A Peñaranda: 22 de noviembre de 1927 y 24 de julio de 1928.

39 En El Adelanto: 1 de julio de 1912, 11 de agosto de 1919, 8 de su familia aparecen como empresarios implicados en causas benéficas (ya fuera por motivos altruistas o mercantiles), y así los encontramos haciendo donativos a diversas entidades (a Los Exploradores Salmantinos, a la Parroquia de Nuestra Señora del Carmen, al Hospicio de Dementes, a la agrupación "Juventud", a la Hermandad de Nuestra Señora de la Soledad $)^{40}$; cediendo instrumentos para eventos musicales y realizando descuentos especiales para asociaciones cultura$\operatorname{les}^{41}$; o bien participando en veladas benéficas ${ }^{42}$. Por último, nuestro empresario forma parte de diversas asociaciones que, a través del pago de cuotas de suscripción, participan en la organización de eventos locales (al Círculo Mercantil para organizar corridas de toros; a la Hermandad del Santo Cristo de la Agonía o a la Patronal de Comerciantes para las celebraciones de la Semana Santa) ${ }^{43}$. Toda esta actividad extra laboral muestra en definitiva una visión inteligente que buscaba afianzar su prestigio como mecenas a nivel local, vinculándolo a su empresa y dando una imagen de solvencia y altruismo al mismo tiempo.

\section{JUAN DE- BERNARDI, ORGANERO: SUS PROYECTOS DE ORGANERÍA ENTRE 1904 Y 1920}

Si a través de la publicidad ofrecida en El Lábaro y El Adelanto hemos seguido la evolución del Juan De- Bernardi empresario y la de su negocio familiar, mediante las constantes reseñas de estos periódicos a sus trabajos en instrumentos ${ }^{44}$ se puede reconstruir su trayectoria como organero entre los años 1904 y 1920, límite temporal acotado por la primera y última intervención en órganos registradas. Estas alusiones a su actividad suelen ser acompañadas de elogios a su trabajo y se ubican en diversas secciones del periódico, que van cambiando a largo de estos años dando fe una vez más del crecimiento de su popularidad, pasando de estar en las "Gacetillas locales", después en las "Noticias varias de la provincia" para llegar, finalmente, a los selectos "Ecos de sociedad".

Apenas un año después de su establecimiento en Salamanca, leemos en las dos transcripciones siguientes que

enero de 1920, 22 de marzo de 1920, 10 de diciembre de 1929.

40 En El Adelanto, respectivamente: 2 de junio, 4 de octubre y 5 de noviembre de 1915; 8 de marzo de 1920; 14 de julio de 1920, 8 de febrero de 1925, 2 de marzo de 1930.

41 El Adelanto, 10 de febrero de 1924 y 11 de febrero de 1930.

42 El Adelanto, 31 de marzo de 1920.

43 En El Adelanto, respectivamente 14 de abril de 1913; 30 de marzo de 1927; 21 de noviembre de 1925.

44 Principalmente órganos, aunque de forma ocasional se dedicaba a arreglar y afinar pianos (El Adelanto, 12 de julio de 1906, en Ciudad Rodrigo). 
De- Bernardi había estado muy ocupado durante meses con la reconstrucción del órgano dieciochesco de la catedral de Miranda do Douro.

Para últimos de mes regresará a esta capital D. Juan DeBernardi, constructor y reparador de órganos y pianos, hallándose actualmente terminando la reconstrucción del órgano de la catedral de Miranda do Douro (Portugal) ${ }^{45}$.

Ha regresado de Miranda do Douro (Portugal) el constructor de órganos, pianos y armoniums D. Juan DeBernardi, donde ha reconstruido un órgano en aquella catedral del vecino reino. Al Sr. De- Bernardi se le ha expedido un documento laudatorio por sus excelentes trabajos realizados en aquella iglesia ${ }^{46}$.

La siguiente noticia que nos llega data de febrero de 1906. En ella se relata que a De- Bernardi se le encargó la tarea de reconstruir casi por completo el órgano del cinematógrafo de Cáceres (aunque, como veremos más adelante, era en realidad un orquestrofón), destruido durante una fuerte lluvia en diciembre de 1905. Dicho órgano debía tener cierta envergadura, ya que el coste del instrumento original ascendió a 30000 pesetas en París, manifestando nuestro organero una gran celeridad en la realización de su trabajo, ya que apenas dos meses después de que el instrumento quedase inhábil, este ya se encontraba en pleno funcionamiento. Una vez más, su trabajo satisfizo a sus clientes y envían una carta a un periódico local de Cáceres, El Adarve, para dar su testimonio que es recogido, a su vez, por El Lábaro y El Adelanto $^{47}$, fieles seguidores de las actividades de este personaje.

Leemos en El Adarve, de Cáceres:

«Hemos tenido ocasión de oír, ya compuesto de los grandes desperfectos sufridos, el órgano propiedad de los dueños del Cinematógrafo que actúa en nuestra plaza señores Sánchez y González.

El órgano que en la noche del 27 de Diciembre, por efecto del terrible aguacero que cayó, quedó por completo destrozado, ha sido compuesto o por mejor decir construido de nuevo por el constructor D. Juan De- Bernardi, que con este fin vino a Cáceres desde Salamanca.

A los Sres. Sánchez y González les hemos oído decir que están admirados de la prontitud, perfección y economía con que ha sido construido un órgano que en

45 El Lábaro. 16 de agosto de 1904.

46 El Lábaro. 5 de septiembre de 1904.

4713 de febrero de 1906 y 15 de febrero de 1906, respectivamente. En ambos casos, el texto recogido por estos diarios no contempla quién firma esa reseña para el periódico norbiense.
París costó 30.000 pesetas y por nosotros mismos hemos comprobado que en efecto el órgano está sin duda en mejores condiciones que antes.

De veras felicitamos al señor De- Bernardi y a los Sres. Sánchez y González, que pueden estar fundadamente satisfechos».

En mayo del mismo año volvemos a tener noticias de De- Bernardi, esta vez con motivo de la reinauguración del recién restaurado órgano barroco del convento de las Úrsulas de Salamanca. Según la noticia, añadió a los registros que el instrumento ya tenía otros que complementaban su base sonora grave, y otros más del gusto romántico como la voz humana, costumbre que ya comentábamos anteriormente. Concretamente sobre esta última señala El Adelanto, a tenor de esta misma noticia, que "en todos los registros, pero especialmente en el de la voz humana, que es de una precisión admirable, la obra del señor Bernardi es la de un muy hábil artista constructor"48.

Ayer tuvimos el gusto de apreciar las importantes reformas efectuadas en el órgano, propiedad de las religiosas Úrsulas, por el notable constructor y reparador de órganos D. Juan De- Bernardi.

Ha añadido diez registros a los ya existentes, entre otros, uno muy bueno de flauta, otro de flautín, de bajos y de voces humanas.

Todos los que escuchamos el órgano reconstruido felicitamos al señor De Bernardi por su nuevo triunfo en su profesión ${ }^{49}$.

Su frenética actividad no cesa durante este año, y poco después leemos una carta dirigida a El Lábaro en la sección "De la provincia". Tal y como indica, es dirigida desde Yecla de Yeltes, una pequeña localidad salmantina en el noroeste de la provincia. Allí De- Bernardi debió realizar una tarea que comenzaría prácticamente desde cero, pues en la carta se especifica que apenas la fachada daba testimonio de que alguna vez hubiera existido allí un órgano. Los clientes quedan tan satisfechos con el trabajo que deciden dejar constancia enviando una carta a El Lábaro el 3 de junio de 1906:

Muy señor mío: con limosnas de varios vecinos de esta villa de Yecla, ha podido repararse el órgano de esta iglesia parroquial, el cual se hallaba en un estado tal de destrucción, que más bien parecía un montón de ruinas, a excepción de la fachada, única señal de que allí existía, o mejor dicho, había existido un órgano.

De esta reparación se encargó don Juan De- Bernardi, residente en esa ciudad, de quien hemos quedado satisfechísimos por habernos dejado un órgano nuevo por una pequeña cantidad ${ }^{50}$.

48 El Adelanto. 9 de mayo de 1906.

49 El Lábaro. 9 de mayo de 1906.

50 El Lábaro. 5 de junio de 1906. La carta, de cuyo contenido 
Ya a finales de año tenemos noticias de su último trabajo de 1906, el del órgano de la parroquia de la localidad cacereña de Brozas. Dicho trabajo se le encomendó quizá debido a la reputación que le precedía tras haber reconstruido el órgano del cinematógrafo de Cáceres, como vimos en la noticia del 13 de febrero de 1906. Aunque en ella llaman "órgano" al instrumento del cinematógrafo, aquí lo denominan "orquestrofón", refiriéndose probablemente al término que el Diccionario Harvard de la Música reconoce como "Orquestrión, un instrumento automático que imita el sonido de toda una orquesta, valiéndose de tubos de órgano y de otros dispositivos controlados por medio de un cilindro, un papel perforado o un mecanismo semejante" ${ }^{51}$. Dicho instrumento reproducía obras famosas y se instalaba frecuentemente en cinematógrafos y cafés para el entretenimiento de los clientes. Esta tradición de instrumentos que reproducen efectos sonoros variados sería bien conocida por Juan De- Bernardi ya que, como indicábamos al comienzo de este artículo, Pedrell señala a su padre como el inventor del "Orquestadeón”, una variante del acordeón.

Pues bien, volviendo de nuevo al instrumento de Brozas, tras restaurar el del cinematógrafo de Cáceres, De- Bernardi probablemente contaba con todas las recomendaciones de los dueños del instrumento para intervenir en otros órganos de la provincia. Y así sería cómo entró en contacto con la localidad de Brozas y restauró el que posiblemente era el órgano dieciochesco de la Iglesia de Santa María la Mayor, añadiendo nuevos registros. Según indica la noticia, su racha continuaría más adelante, pues se le encomendarían las restauraciones de los órganos de las parroquias de San Juan y Santa María de Cáceres.

De Brozas nos escriben diciendo que reina gran entusiasmo entre los fieles porque el antiguo órgano parroquial, que estaba completamente destrozado, ha sido construido de nuevo por el distinguido D. Juan DeBernardi y viene tocándose en las fiestas religiosas.

El Sr. De- Bernardi, que como nuestros lectores recordarán demostró en Cáceres su pericia arreglando el orquestrofón que los señores Sánchez y González tenían en su cinematógrafo, ha puesto registros nuevos al órgano de Brozas, que hoy está completamente afinado y emite notas delicadísimas. Muy brevemente tan distinguido mecánico músico llegará a Cáceres, donde arreglará los órganos de San Juan y Santa María ${ }^{52}$.

ofrecemos aquí un extracto, está firmada por Juan Aparicio quien, por el texto de la misiva, deducimos que era el párroco de la localidad (que por cierto cuenta a día de hoy con una calle dedicada a él). 51 RANDEL (1999): 770.

52 El Lábaro. 12 de noviembre de 1906.
Sobre su trabajo en dicha parroquia de Santa María se habla en una reseña en la revista semanal Alma Extremeña, y de nuevo El Lábaro "caza” esta noticia para hacerse eco de ella y mantener con ello la reputación de aquél que tan fieles ingresos les procuraba. En este nuevo recorte que transcribimos encontramos datos interesantes, al margen de las consabidas alabanzas a la profesionalidad y buen hacer de De- Bernardi y de la instalación de voces humanas románticas en un órgano barroco, como solía hacer. Se nos habla, además, de un elemento del que hasta el momento no habíamos tenido noticia, y es el "fuelle sistema Bernardi" 53 . Igualmente se nos informa de su siguiente trabajo, en la parroquia de Santiago de Cáceres.

\section{Copiamos del Alma Extremeña:}

«En algunos de nuestros colegas hemos leído una noticia felicitando al constructor de órganos D. Juan De- Bernardi, vecino de Salamanca, por las reparaciones que ha hecho en el parroquial de Santa María. Nosotros, sentimos mucho no disponer de espacio para hablar detenidamente del Sr. Bernardi, verdadero y notable artista en toda la extensión de la palabra.

El viejo órgano de Santa María queda hoy completamente reformado gracias a la pericia del reconstructor; ha sido aumentado en sus registros, reforzado en los tubos y se le ha puesto un nuevo fuelle (sistema Bernardi) que es una verdadera preciosidad. De afinación y voces, cuanto pudiera afirmarse resulta pálido ante la realidad con la imitación de voces humanas en coro, los solos de soprano, etc., recuerda la hermosa música de nuestras históricas catedrales.

Las reformas que el Sr. Bernardi llevará a cabo en el órgano de Santiago, serán de mayor importancia y en ellas seguramente patentizará el artista su exquisito gusto. Nuestra enhorabuena al Sr. Bernardi y a los párrocos que acordaron tan necesaria medida» ${ }^{54}$.

Por fin termina un ajetreado año 1907 en el que su actividad se había centrado en la provincia de Cáceres (Brozas, y las parroquias de San Juan, Santa María y Santiago en la capital de provincia), volviendo a su mercado más fiel, el salmantino, para restaurar el órgano de la Parroquia de El Salvador de Béjar.

53 Aunque aquí no explican en qué consiste este "fuelle sistema Bernardi", nos podemos remitir al informe realizado por el propio DeBernardi sobre el órgano Amezua de la parroquia de la Purísima Concepción de Salamanca: "El sistema de entonar el fuelle es sumamente costoso o fatigoso, y es necesario reformarlo por el de sistema pendular (especialidad mía) que la podrá entonar un niño de 12 o 14 años sin cansarle y sin producir ruido alguno". (Libro de Régimen, fol. 6v. Archivo Parroquial de la Purísima Concepción, Salamanca). 54 El Lábaro. 30 de abril de 1907. 
Se encuentra en Béjar practicando un importante arreglo en el órgano de la iglesia parroquial del Salvador, nuestro amigo D. Juan De- Bernardi, inteligente constructor de órganos y hábil compositor de pianos y armoniums, establecido en Salamanca ${ }^{55}$.

Y después de tanta actividad, no encontramos noticias acerca de él hasta un año después de la última, en julio de 1908, en que aparece de nuevo para hacernos saber que ha restaurado el órgano de Santa María la Mayor de Ledesma (Salamanca): "Ha regresado de Ledesma don Juan De Bernardi, donde acaba de ejecutar una importante reforma en el órgano de Santa María la Mayor" ${ }_{56}$. Y precisamente sobre este órgano versa el recorte la siguiente crónica, que reseña un concierto que se celebró tras la reparación de este órgano por De- Bernardi quien, además de aumentar la potencia de los registros ya existentes y posiblemente modificar el sistema de afinación previo, una vez más añadió elementos románticos (como el trémolo o la caja expresiva) a un órgano que, a pesar de datar de $1803^{57}$, muestra una disposición dieciochesca.

La misa fue acompañada por el maestro organista, también hijo de esta población, D. José Verdi Conde, en el órgano recientemente reformado por el reputado constructor de órganos D. Juan De- Bernardi, habiéndole aumentado varios registros de gran efecto como son: Trémolo, Caja-Expresiva, Violón, etc., y dado mayor potencia de voz a los demás registros, quedándole con voces melodiosas y potentes a la vez, y afinación perfecta en todos los diferentes registros que contiene en los dos teclados de cuya notable reforma han quedado sumamente satisfechos, no sólo el Sr. Arcipreste de dicha iglesia, sino todo el pueblo en general $^{58}$.

Ya en 1909 encontramos por fin una noticia en la que Juan De- Bernardi no es el restaurador, sino el artífice de un órgano de nueva construcción: el de la iglesia del Colegio de Salesianos de Salamanca. A lo largo de ese año se terminó la construcción de dicho colegio, acontecimiento que recoge $\mathrm{El}$ Adelanto en dos ocasiones ${ }^{59}$, pero centrándose en los aspectos arquitectónicos del edificio y mencionando apenas la existencia de un órgano en el coro de la capilla. El Lábaro, en cambio, sí anuncia su inauguración para el día 5 de noviembre de 1909: "Mañana viernes a las tres de la tarde se inaugurará en la

55 El Lábaro. 17 de junio de 1907.

56 El Lábaro. 7 de julio de 1908. Noticia también recogida en $E l$ Adelanto, 7 de julio de 1908.

57 http://www.organaria.es [Consultada el 3 de marzo de 2017]. 58 El Lábaro. 23 de julio de 1908.

59 El Adelanto, 11 de octubre y 13 de junio de 1910. iglesia del Colegio de Salesianos de esta ciudad el nuevo órgano construido por don Juan De- Bernardi. Al acto hemos sido atentamente invitados" ${ }^{\prime 60}$. Y así lo confirman sendas reseñas de contenido similar en ambos periódicos dos días después, incluyendo algunas especificaciones sobre su morfología:

En la tarde de ayer se ha efectuado la bendición y prueba oficial del órgano de la capilla de los padres Salesianos, siendo tocado y examinado por los señores Mingote, Pinedo y organista salesiano quedando sumamente satisfechos de la obra hecha por el señor De- Bernardi, resultando esta perfecta, pues todo su mecanismo contiene todos los adelantos conocidos. Los sonidos son dulces y llenos.

Este órgano consta de dos teclados manuales y uno para los pies, con siete pedales de combinación y diez juegos de tubería, sistema mecánico y consola, resultando que la obra no deja nada que desear y pueden estar satisfechos los padres Salesianos de tener un órgano bien construido, y felicitamos a su constructor don Juan De- Bernardi ${ }^{61}$.

Llegamos por fin a 1910, último año de publicación de El Lábaro, y éste se despide de su fiel cliente con dos reseñas. La primera alude a la restauración del órgano de la localidad salmantina de Ciudad Rodrigo, sin que se nos den más detalles al respecto: "Ha regresado de Ciudad Rodrigo, después de hacer grandes reparaciones en el órgano de la Catedral, Juan De- Bernardi" "62. La segunda se refiere a la instalación de un órgano nuevo en la población de Cáceres, si bien no especifican el lugar exacto: "De Cáceres, en cuya población ha estado instalando un órgano, ha llegado el maestro constructor don Juan de Bernardi"'63. En este caso nos ayuda El Adelanto, que un día después publica en "Notas de sociedad" la misma noticia anunciando que ha vuelto de viaje desde tras instalar un órgano en el santuario de la Virgen de la Montaña, sito a las afueras de dicha localidad: "De Cáceres, donde ha estado instalando un órgano, en el Santuario de la Montaña, don Juan De- Bernardi, nuestro particular amigo" 64 .

Una vez que El Lábaro deja de editarse, será El Adelanto la única fuente hemerográfica digitalizada que nos ayude a conocer su itinerario durante los siguientes veinte años. Sin embargo sólo se han encontrado tres intervenciones durante este período, lo que indica que, o bien este periódico no registra su actividad con el mismo celo que su predecesor; o bien (y más probable) el empresario, debido a
60 El Lábaro. 4 de noviembre de 1909.

61 El Adelanto. 6 de noviembre de 1909.

62 El Lábaro. 28 de marzo de 1910.

63 El Lábaro. 29 de agosto de 1910.

64 El Adelanto. 30 de agosto de 1910. 
la expansión de su negocio mediante la apertura de tiendas destinadas a un público más diversificado, redujo su labor como organero para abandonarla definitivamente en 1920 , ya con su empresa plenamente consolidada y dando comienzo a la década dorada de los De- Bernardi en Salamanca.

De estas tres intervenciones, la primera tiene lugar en 1914 en la localidad portuguesa de Covilha, donde instala un instrumento de nueva construcción: "De Covilha (Portugal), de montar un órgano de gran tamaño, el conocido almacenista de pianos don Juan De- Bernardi"65. La segunda, pocos días después, se lleva a cabo en la propia Salamanca, donde restaura el órgano de la iglesia de San Martín (¿tal vez San Martín de Tours?): "Nuestro querido amigo el conocido constructor de órganos, don Juan De Bernardi, ha comenzado la reconstrucción del antiguo órgano de la parroquia de San Martín"66. Y por último, vuelve a Béjar en 1916, aunque no se especifica su trabajo allí.

Desde hace dos días se halla en Béjar mi querido amigo don Juan De Bernardi, tan conocido en Salamanca como constructor y reparador de pianos y órganos.

El señor Bernardi, que es un gran artista, permanecerá muchos días en Béjar, donde tiene preparado mucho trabajo que le proporciona su bien cimentada fama ${ }^{67}$.
Aparte de las noticias proporcionadas por los periódicos, también encontramos en internet referencias a De- Bernardi y a su paso por los órganos, como ya hemos dicho, de la Catedral de Ciudad Rodrigo y del Santuario de Nuestra Señora de la Montaña, las cuales hemos podido documentar con fuentes de la época; a ello habría que añadir otras que no hemos podido contrastar (y que por lo tanto no hemos incluido aquí), como su intervención en 1917 en el órgano de la parroquia de la localidad salmantina de Palaciosrubios ${ }^{68}$.

Por fin, concluimos esta década con la intervención que fue el objeto original de esta investigación, la del órgano de la parroquia de la Purísima Concepción de Salamanca, $\mathrm{y}$ en el que no nos detendremos por ser objeto ya de otro estudio $^{69}$. Gracias a las actas parroquiales, conservamos la memoria realizada por el propio De- Bernardi para la restauración, que requería desmontar y limpiar toda la tubería, arreglar los mecanismos neumáticos y mecánicos, reformar la voz humana para que no fuera tan lenta en responder, corregir los canales de aire de los fuelles y, por fin, sustituir el sistema de suministro de aire, es decir, la fuellería en $\mathbf{s i}^{70}$.

Tras este repaso al itinerario profesional de este organero en las dos primeras décadas del siglo $\mathrm{XX}$, podemos ver en el mapa adjunto (figura 8) el área desde el que era solicitado y conocido, gracias probablemente al muy eficaz "boca a boca".

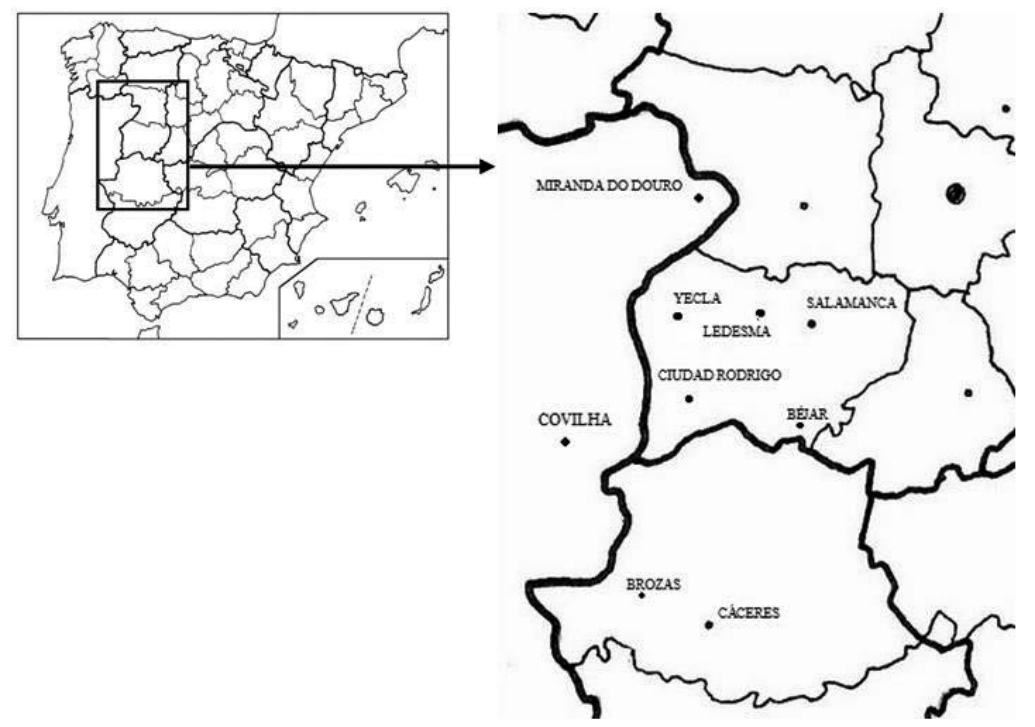

Fig. 8. Área de trabajo de Juan de- Bernardi entre 1903 y 1920

65 El Adelanto. 10 de agosto de 1914.

66 El Adelanto. 22 de agosto de 1914.

67 El Adelanto. 9 de mayo de 1916.
$68 \mathrm{http}: / /$ palaciosrubios.org/?page_id=210 [Consultado el $10 \mathrm{de}$ abril de 2017].

69 GARCÍA MARTÍN, 31 (2015): 149-184.

70 Esta información se encuentra en el único Libro de Régimen presente en el archivo parroquial. 


\section{LA CONTINUIDAD DE UNA VOCACIÓN MUSICAL: EL "JOVEN, DISTINGUIDO Y REPUTADO MAESTRO LUIS DE- BERNARDI"}

Aunque Juan De- Bernardi fue principalmente un empresario, no vio inconveniente en participar ocasionalmente en la actividad musical salmantina. Y así nos lo encontramos implicado activamente como compositor ${ }^{71}$ o como intérprete. Adjuntamos un extracto del anuncio de un concierto y crónica posterior ${ }^{72}$ :

Programa de la velada musical organizada por el Orfeón "El Duero" que tendrá lugar esta tarde a las cinco y media en referido teatro $[\ldots]$. Tercera parte. $1^{\circ}$ "Ingrata". Retana. Zortzico, por el Orfeón. $2^{\circ}$ Romanza de barítono por el solista del Orfeón don Julio González. $3^{\circ}$ "El Torbellino". Titto Mattei, valses de concierto. $4^{\circ}$ "Obertura de Poeta y Aldeano". Suppé. Estos dos números estarán a cargo del eminente artista italiano y constructor de órganos y pianos, recientemente establecido en esta ciudad, don Juan De- Bernardi, que los interpretará en el instrumento de su invención, conocido con el nombre de “orquestadeón”...

El sexteto fue también muy aplaudido, y lo mismo el señor De- Bernardi, que sabe sacar del orquestadeón, instrumento de su invención, efectos admirables y tiene en él una ejecución prodigiosa.

Sin embargo, sería su descendencia la que asumiría la difícil e itinerante profesión del músico, y de entre sus 9 hijos, Luis De- Bernardi fue el que alcanzó mayor reconocimiento en este campo, siendo un artista versátil y muy activo en los diferentes ámbitos de la vida musical salmantina.

Su debut en la escena musical de Salamanca vino de la mano de su participación en un fenómeno peculiar y aún poco estudiado: el de las compañías infantiles de zarzuela, muy populares durante el siglo XIX y que, al parecer y según las noticias que relataremos a continuación, aún pervivían a principios del XX. Sobre dicho fenómeno se ha presentado algún estudio recientemente que se encuentra en su fase inicial, por tratarse de un tema novedoso ${ }^{73}$.

71 En una ocasión figura como el autor de una marcha que interpreta la Tuna Escolar en un concierto en el Liceo. El Adelanto, 16 de febrero de 1911.

72 El Adelanto, 10 y 11 de enero de 1904, respectivamente. Si nos atenemos a la definición de "orquestadeón" que hace Pedrell en su Diccionario técnico, el inventor en realidad habría sido el padre, Nicolás De- Bernardi.

73 CLARES CLARES (2016): 75.
Así pues lo encontramos, aún niño, como integrante del reparto de una compañía infantil que actúa en el Liceo de Salamanca, representando fragmentos de diversas zarzue$\operatorname{las}^{74}$. La primera, Una comedia en un pueblo, era probablemente de inspiración local, pues la noticia comenta que los niños iban vestidos con los "clásicos trajes charros". En esta misma representación Luis De- Bernardi actuará como parte del "Coro de los doctores" de la zarzuela El rey que rabió (Ruperto Chapí, 1884) y del "Coro de marineros" de Los dos genios (José Fornet, 1902). En ambos casos, entre los compañeros que tiene De- Bernardi en el coro infantil, figuran nombres vinculados a personajes destacados del panorama musical local, como "Hilarito Goyenechea" o "Luciano Sánchez Fraile", aludiendo evidentemente a familiares del que sería maestro de capilla de la Catedral de Salamanca, y del compositor Aníbal Sánchez Fraile, respectivamente.

Algún tiempo más tarde Luis tiene un papel más relevante, en este caso como pianista acompañante de la compañía, en una representación en el Colegio de los Salesianos (el mismo, por cierto, en cuya capilla su padre había instalado un órgano tres años antes), en la que ofrecieron los juguetes cómicos Los asistentes (Pablo Parellada, 1895) y El catedrático de anatomía (Antonio J Onieva, 19--i): "Solo hemos de consignar los aplausos merecidísimos que se tributaron al niño Luis De- Bernardi, precoz artista que cautivó al público por la soltura y gracia con que toca el piano"75. Una vez dejó de formar parte del grupo coral de esta compañía, no se desvincularía del todo, pues en ocasiones ejerce de profesor y pianista acompañante en las representaciones infantiles ${ }^{76}$, e incluso otros miembros más jóvenes de la familia seguirían su mismo camino, como Fernando, a quien encontramos en el reparto de un sainete lírico representado en la Academia del Liceo Salmantino ${ }^{77}$.

Mientras tanto, el "precoz artista" se encontraba realizando sus estudios de música, probablemente tomando clases como alumno libre del maestro de capilla de la catedral Hilario Goyenechea ${ }^{78}$, y examinándose en el Conservatorio de Música y Declamación de Madrid en 1914, 1915 y 1916, respectivamente:

El prodigioso niño de once años, Luisito De- Bernardi, hijo del almacenista de música y afinador de pianos de esta localidad, don Juan De- Bernardi, después de

74 El Adelanto, 23 de enero de 1911.

75 El Adelanto, 2 de diciembre de 1912.

76 El Adelanto, 26 de octubre de 1915, 29 de enero de 1926 y 17 de noviembre de 1926.

77 El Adelanto, 31 de octubre de 1926.

78 El Adelanto, 14 de agosto de 1928. 
brillantísimos ejercicios, ha obtenido las calificaciones de tres sobresalientes en los tres cursos de solfeo, y tres sobresalientes en los tres primeros cursos de piano, habiendo llamado la atención la seguridad y aplomo con que hizo los ejercicios ${ }^{79}$.

El niño Luisito De- Bernardi, de doce años, hijo de nuestro querido amigo don Juan De- Bernardi, después de unos notabilísimos ejercicios, de los que se ha ocupado con elogio la prensa de Madrid, ha merecido que el Conservatorio premiara su precoz talento musical, concediéndole, a pesar de su edad el título de profesor elemental de música ${ }^{80}$.

Después de brillantes ejercicios en los que ha obtenido las notas de sobresaliente, ha aprobado en el Conservatorio de Madrid, los años sexto y séptimo de piano, el niño Luis De- Bernardi, hijo de nuestro querido amigo don Juan. Felicitamos al niño y a sus padres, así como también a su profesor, don Hilario Goyenechea ${ }^{81}$.

Durante los últimos años de formación, Luis De- Bernardi compatibiliza sus estudios con algunas intervenciones tocando el armónium en la iglesia de los Carmelitas (antiguamente Iglesia de la Magdalena) con motivo de celebraciones especiales, como comuniones, fiestas sacramentales o la celebración del IV Centenario de Santa Teresa ${ }^{82}$.

Tras terminar la carrera, Luis ejercerá como profesor de estudiantes de piano libres que, como él hizo en su momento, iban a Madrid a examinarse, y así encontramos entre 1920 y 1928 noticias de cuatro de alumnas (aunque seguramente fueron más): Carmen Vicioso, Pepita González, Eladia Villanueva Clemente y Balbina Carrar Castilla, que aprobaron estos ejercicios con calificaciones de sobresaliente en varios cursos y como final de carrera en las materias de solfeo, piano y armonía ${ }^{83}$.

A partir de 1920 comenzará con su actividad concertística adulta, participando en diversos ámbitos de la vida musical salmantina. Fue significativa su implicación en los actos de homenaje a Tomás Bretón tras su muerte, tocando la misa de Perosi en sus funerales o en actos conmemorativos posteriores $^{84}$. Es frecuente también encontrarle interpretan-

79 El Adelanto, 8 de julio de 1914.

80 El Adelanto, 30 de junio de 1915.

81 El Adelanto, 23 de junio de 1916.

82 Respectivamente, en El Adelanto, 20 de marzo de 1915, 23 de noviembre de 1915 y 30 de marzo de 1916.

83 El Adelanto, 22 de junio de 1920, 7 de octubre de 1926, 30 de junio de 1927 y 3 de julio de 1928 , respectivamente.

84 El Adelanto, 11 de diciembre de 1923; 27 de diciembre de do música en bodas, tanto al armónium o piano en solitario como con grupos instrumentales; y tanto repertorio religioso en la ceremonia ${ }^{85}$, como bailables en los banquetes ${ }^{86}$, frecuentando en estos eventos lugares como la Iglesia de San Martín, la parroquia del Carmen, el Café Novelty, el Hotel Términos o el Hotel Comercio.

Precisamente con la parroquia de Nuestra Señora del Carmen (sita en la Plaza de los Bandos de Salamanca) tenía la familia De- Bernardi una relación de proximidad, tal vez porque la vivienda familiar se encontrase cercana a dicha iglesia (y también al local de su negocio). En ella Juan DeBernardi realizaba donaciones; su hijo Luis actuaba allí con asiduidad tocando el armonio, con grupo instrumental o dirigiendo un coro de señoritas en diversas ceremonias como las fiestas sacramentales, bodas o comuniones ${ }^{87}$; varios de sus hijos tomaron allí su primera comunión ${ }^{88}$; y el propio Luis De- Bernardi celebró allí su matrimonio con Carmen Santos de la Mata, hija del comisario de guerra de Salamanca ${ }^{89}$.

En sus primeros años como intérprete, sus actuaciones musicales tienen que ver en ocasiones con causas benéficas, colaborando con agrupaciones como la Asociación de Señoras y Señoritas para el Mejoramiento Moral y Material del Obrero, la Cruz Roja o el Sindicato de Acción Social Católica, cuyos eventos amenizaba con música de forma gratuita ${ }^{90}$.

Pero su principal actividad musical profesional va a ser llevada a cabo a través del grupo instrumental que dirigía y que, según algunas crónicas, tocaba habitualmente en el teatro Liceo $^{91}$. En este grupo actuaba un número variable de integrantes (desde el trío hasta el septeto), llegando a formarse un

85 El Adelanto, 3 de abril, 7 de junio de 1925, 3 de septiembre de 1926, 8 de octubre de 1927,15 de abril y 26 de junio de 1928 .

86 El Adelanto, 9 de julio 1921, 26 de agosto de 1924, 11 de marzo y 17 de septiembre de 1926.

87 El Adelanto, 22 de mayo de 1925, 14 de mayo de 1926, 27 de mayo de 1927, 8 de octubre de 1927, 15 de abril de 1928, 26 de junio de 1928.

88 Concepción De- Bernardi el 26 de mayo de 1922, José DeBernardi el 22 de mayo de 1925, Ángel De- Bernardi el 14 de mayo de 1926.

89 En El Adelanto, pedida de mano reseñada el 20 de julio de 1927 y crónica de la boda el 29 de septiembre de 1927.

90 El Adelanto, 26 de octubre de 1915, 16 de mayo de 1921; 5 de septiembre de 1921, respectivamente.

91 Antonio Gallego hace alusión al fenómeno de las agrupaciones de músicos que, buscando la protección del asociacionismo, se vinculaban en conjuntos que actuaban en períodos en los que los teatros cerraban, tocando en su lugar en cafés, hoteles, balnearios... con un repertorio de salón, generalmente arreglado para sextetos o septetos. GALLEGO, 14, 1-2 (1991): 29. Según Gallego, estos repertorios eran interpretados por esta tipología de agrupaciones principalmente en ciudades que no contaban aún con asociaciones de conciertos, y la Sociedad Filarmónica de Salamanca no se constituiría hasta 1948. GEJO SANTOS (2015): 464. La agrupación de Luis De- Bernardi encajaría en este perfil. 
conjunto independiente que se hacía llamar Les Tay Wer, cuyo catálogo habitual eran los "bailables de moda" que tocaban en las veladas del Casino con motivo de los carnavales ${ }^{92} \mathrm{o}$ los bailes del Círculo del Pasaje coincidiendo con diversas festividades (la Purísima, las Candelas...) ${ }^{93}$. Esta agrupación conocía el repertorio de las primeras bandas de jazz y lo interpretaba en diferentes contextos como en bailes de la Helmántica en los que "las parejas bailaron las danzas de moda, fox- trot y one step" o acompañando películas en el cinematógrafo, al que se presentaban como jazzband ${ }^{94}$.

Otra de sus facetas como músico profesional recaía en la dirección de la Tuna Escolar de Salamanca, que debía estar formada por universitarios o al menos bachilleres ${ }^{95}$, con la que ensayaba en la Casa Rectoral de la universidad y en el Palacio de Anaya ${ }^{96}$ en los últimos meses de cada año de cara a las celebraciones de Carnaval $^{97}$, que realizaba giras por ciudades cercanas ${ }^{98}$ y ofrecía frecuentes actuaciones en el Liceo o el Casino hasta la llegada de la Cuaresma ${ }^{99}$.

La carrera musical de Luis no se desarrolló solo en la capital salmantina, sino que viajó por varias poblaciones con su grupo instrumental, interviniendo en las fiestas locales o celebraciones carnavalescas. Así, encontramos actuando en el Casino de Zamora con motivo de los carnavales a la "notable agrupación orquestal que dirige el joven profesor Sr. De- Bernardi y que con unánime aplauso viene actuando a diario en el teatro del Liceo"; en el Casino de Béjar, también en carnavales el "Cuarteto Bernardi" integrado por "los conocidos y competentes profesores de la orquesta del teatro Liceo, don Luis Bernardi, don Eloy Andrés, don Clemente Tomás y don Pablo Ceballos"; y en el Casino de Guijuelo en las fiestas locales y en los carnavales ${ }^{100}$.

92 El Adelanto, 22 de septiembre de 1921, 16 de febrero de 1926, 1 y 2 de marzo de 1927.

93 El Adelanto, 9 de diciembre de 1921, 3 de febrero de 1922, 16 de junio de 1922 y 9 de diciembre de 1927.

94 El Adelanto, 14 de enero de 1922 y 10 de abril de 1924. Para más información sobre los primeros años del jazz en España y el repertorio de las agrupaciones, consultar GARCÍA MARTÍNEZ (1996).

95 El Adelanto, 18 de enero de 1930.

96 El Adelanto, 20 de enero de 1927 y 6 de enero de 1928, respectivamente.

97 El Adelanto, 13 de diciembre de 1927.

98 "Este año, los escolares que forman la Tuna Universitaria Salmantina han querido aprovechar el tiempo y han adelantado un poquito su anual excursión artística. Estos proyectos van encaminados a estar de regreso en Salamanca antes de finalizar las vacaciones de Navidad. Así, desde hace algunos días, se han dedicado a dar serenatas, para después finalizar con la velada en honor de sus presidentes, y probablemente el día 12 saldrán por varias capitales españolas" (El Adelanto, 10 de diciembre de 1930). Zamora era una de las habituales (El Adelanto, 28 de enero de 1930). 99 El Adelanto, 9 y 10 de febrero de 1927, 17 y 27 de enero de 1928.

100 El Adelanto, 6 de marzo de 1923, 4 de marzo de 1925, 15 y 20 de febrero de 1929, 14 de agosto de 1931, 17 de febrero de 1932 .

\section{"LAS DISTINGUIDAS SEÑORITAS DE- BERNARDI": UNA FAMILIA INSERTA EN LA ALTA SOCIEDAD}

Como decíamos antes, una vez que la familia se encuentra plenamente asentada en la ciudad, la prensa comienza a recoger muchos de sus movimientos, normalmente a través de secciones como los "Ecos de sociedad". En ellos nos enteramos de datos curiosos que nos dan pistas sobre el estilo de vida de una familia burguesa de principios de siglo en Salamanca. Así, conocemos las características de sus vacaciones, que solían durar un mes entre julio o agosto, en lugares en la sierra o de la costa, como Béjar, Sequeros, el Puerto de Béjar, Plasencia, Gijón o Santander ${ }^{101}$; nos enteramos del nacimiento de los hijos pequeños de la familia, María y José ${ }^{102}$; de los colegios en los que estudiaban ${ }^{103}$; de las festividades fuera de Salamanca que frecuentaban, como los carnavales de Ciudad Rodrigo o el Corpus en La Fregeneda $^{104}$; e incluso de cómo esta familia asumió prácticas propias de las clases acomodadas, como el pagar una cantidad de dinero para evitar que sus hijos tuvieran que hacer el servicio militar ${ }^{105}$.

Al respecto de su actuación en las fiestas locales de Guijuelo en 1931, la noticia recogida por el periódico realiza una corrección, indicando que previamente habían anunciado que las fiestas serían amenizadas por la orquesta de Bernalt, pero finalmente lo serían por la de Bernardi, lo que nos lleva a pensar que existiría una sana competencia entre ambos grupos, y que la actividad de De- Bernardi estaba a la altura de la de una personalidad musical como García- Bernalt.

101 El Adelanto, 23 de agosto de 1924; 9 de junio de 1927; 14 de julio y 16 de agosto de 1927; 29 de julio y 2 de septiembre de 1928 ; 7 de agosto de 1929; 11 y 14 de julio de 1929; 25 de julio de 1931. Es posible que en alguna ocasión también veraneasen en Portugal, ya que el 15 de agosto de 1915 una noticia narra cómo las familias acomodadas de Salamanca, entre ellas la De- Bernardi, habían cogido "El Botijo", que en el caso de Salamanca era el tren que enlazaba con Figueira da Foz para llevar a los veraneantes a las playas de Portugal (http://tierracharra.blogspot.com.es/2011/06/el-tren-botijo-figueira-da-foz.html, consultado el 28 de febrero de 2017).

102 El Adelanto, 5 de diciembre de 1914 y 20 de abril de 1916, respectivamente. El 12 de febrero de 1908 se anuncia el nacimiento de una de las hijas mayores que, por las fechas, podría ser Julia.

103 Es probable que los niños estudiasen en el colegio de los Salesianos, ya que en una ocasión Ángel De- Bernardi aparece como uno de los alumnos premiados del centro (22 de diciembre de 1929); y las niñas en el colegio del Sagrado Corazón (Jesuitinas) y las Siervas de San José, donde se reseñan entregas de premios a alumnas con veladas musicales (Julia De- Bernardi el 23 y 26 de junio de 1915) y ocasionalmente participaban en exposiciones de labores (Lola De- Bernardi el 27 de junio de 1929 y 26 de junio de 1930).

104 El Adelanto, 17 de febrero de 1920, 26 de febrero de 1925, 15 de junio de 1928.

105 El 20 de febrero de 1922 se sortearon los quintos, saliendo entre ellos Juan De-Bernardi (hijo). El 31 de mayo de 1924 se publican las resoluciones del juicio por exenciones de reclutamiento militar, del 
Sin embargo no es mi intención aburrir al lector con un extenso anecdotario relativo a los De- Bernardi, que incluiría incidentes callejeros ${ }^{106}$, asistencia como invitados a bodas de cierta relevancia social ${ }^{107}$, los matrimonios que contrajeron los hijos mayores ${ }^{108} \mathrm{o}$ incluso reseñas de las enfermedades por las que pasaban ${ }^{109}$. Sí me interesa, en cambio, que esta sección sirva para dar una idea de cuál era la presencia e implicación en la actividad cultural salmantina de una familia de clase media- alta dedicada a la empresa musical.

De entre todos los integrantes de esta numerosa familia, quienes van a ser reseñadas con más frecuencia en eventos sociales, aunque casi siempre como participantes pasivas, serán sin duda María Romero y sus hijas Julia y Lola De- Bernardi, probablemente en una misión de búsqueda de candidatos con los que las jóvenes pudieran contraer matrimonio. Es habitual su asistencia a bailes regulares de temporada y veraniegos en el parque de recreo de El Rollo, el Casino o Las Torres ${ }^{110}$; a los bailes de confianza que el Casino ofrecía a sus socios ${ }^{111}$; o a los bailes de Carnaval y del

que quedaría excluido temporalmente posiblemente por haber pagado la cantidad de 1000 pesetas, devuelta más tarde por Hacienda (6 y 13 de septiembre de 1925) una vez terminada la exención temporal.

$106 \mathrm{El}$ Adelanto nos cuenta dos incidentes curiosos. El primero se produce el 4 de noviembre de 1924 , en que se da la noticia de que Fernando De- Bernardi atropelló con la bicicleta en la calle de la tienda de su padre a un transeúnte que, a su vez, abofeteó al ciclista. El segundo tiene lugar el 30 de septiembre de 1931 cuando, durante una huelga general de la Federación Obrera, se producen unos disturbios durante los cuales una pedrada rompe la luna de la tienda familiar.

107 El Adelanto, 27 de diciembre de 1924, 20 de marzo de 1925, 22 de enero de 1928.

108 Juan De- Bernardi (hijo) se casa con Exaltación Sánchez. Se anuncian las amonestaciones el 31 de octubre de 1924 y el 25 de noviembre se anuncia la boda para el día $30 \mathrm{del} \mathrm{mismo} \mathrm{mes.} \mathrm{Las} \mathrm{amones-}$ taciones para el enlace de Julia De- Bernardi con el médico destinado en Asturias José G. de la Vega se anuncian el 1 de noviembre de 1929 y la boda se señala para los primeros 10 días de diciembre del mismo año, tras la cual Julia abandona Salamanca para trasladarse al destino de su marido, Caravia (15 de mayo de 1930), donde tendría su primera hija (7 de diciembre de 1930). Y, como hemos dicho antes, Luis De- Bernardi se casaría en 1927 (ver nota 89). Todas estas noticias están recogidas en El Adelanto en las fechas indicadas.

109 El Adelanto, 14 de enero de 1925, 22 y 26 de junio de 1926, 13 de octubre de 1926 .

110 El Adelanto, 29 de julio de 1920; 27 de febrero de 1922; 4 de marzo de 1924; 2 de febrero y 6 de abril de 1926; 3 de febrero de 1929.

111 Luis Mariano de Larra escribió sobre estas actividades en su Reuniones de confianza (1887), que describía como reuniones en las que la clase media que quería ser aristocrática, era recibida para charlar, jugar a algún juego de sociedad de moda y tomar un chocolate. Los eventos a los que van a ir nuestras señoritas De- Bernardi incluirán además el baile. Las fechas en las que su asistencia a estos actos queda registrada en El Adelanto son: 4 de diciembre de 1904, 30 de abril de 1906, 27 de diciembre de 1910, 20 de febrero de 1923, 24 de febrero de 1925 y 1 de marzo de 1927. primer domingo de la Cuaresma, también conocido como Domingo de Piñata, en el cual se organizaba una última velada antes de la austeridad que impone el período previo a la Semana Santa ${ }^{112}$. Las mujeres De- Bernardi también eran asiduas a otro tipo de reuniones sociales: los thé dansant $\mathrm{o}$ tea dance, que tenían lugar a lo largo de la tarde (aproximadamente entre las 4 y las 7) en lugares como el Novelty, Las Torres o el Casino ${ }^{113}$.

Aparte de los bailes de confianza ofrecidos de forma regular e independiente por instituciones como El Casino o El Pasaje, o de los que tenían lugar con motivo de festividades, diversas asociaciones culturales de la ciudad organizaban sus propias reuniones y verbenas a las que las señoritas no podían faltar para dejarse ver en sociedad, a veces en los mismos salones que hemos mencionado. Por ejemplo, las reuniones promovidas por los alumnos de la Academia de Caballería en El Casino ${ }^{114}$, el "Baile de los Lunes" de la Helmántica ${ }^{115}$, las verbenas veraniegas de la Unión Deportiva ${ }^{116}$ o los bailes que la Asociación de Prensa ofrecía en el Liceo en invierno y en el antiguo Frontón de San Bernardo (hoy la explanada del Parque de San Francisco) en verano ${ }^{117}$.

Por otra parte, y siguiendo con la tradición que asociaba las tareas del cuidado a las mujeres, las de esta familia se implican en actos benéficos que incluyen actuaciones musicales, con conciertos en el Liceo cuya recaudación se destina a organizaciones benéficas como La gota de leche; o participando en el comité de mujeres que organizaron los festejos para celebrar la visita a Salamanca de Alfonso XIII y la infanta Doña Beatriz ${ }^{118}$.

Por supuesto, como cualquier familia que estuviera en el candelero, los De- Bernardi tenían abonos de temporada y de ferias a los principales teatros de Salamanca: el Bretón y el Liceo, y aunque ocasionalmente vemos a Juan padre e hijo señalados entre los asistentes (que normalmente se dejan ver en los estrenos de la temporada), las visitantes más

112 El Adelanto, 25 de febrero y 2 de marzo de 1905; 21 de febrero de $1912 ; 15$ y 17 de febrero de $1915 ; 4$ de marzo de $1916 ; 17$ de febrero de $1920 ; 18,21$ y 25 de febrero de $1925 ; 14,17$ y 23 de febrero de 1923; 2 de marzo de 1927; 12 de febrero de 1929 .

113 Los thé dansant a los que acuden las hijas mayores de la familia De- Bernardi (acompañadas siempre de la progenitora que velara por su moralidad, como indica GARCİA MARTÍNEZ (1996): 41), se celebraban con motivo de las fiestas de Navidad o de Carnavales. 28 y 30 de diciembre de 1922; 26 de diciembre de 1924; 20 de enero de 1929; 13 y 19 de febrero de 1929 .

114 El Adelanto 30 de abril de 1915.

115 El Adelanto, 14 de enero de 1922 y 27 de junio de 1922.

116 El Adelanto, 29 de junio de 1924, 30 de junio de 1925, 30 de junio de 1927, 25 de junio de 1929 .

117 El Adelanto, 27 de febrero de 1927, 10 de febrero de 1929, 25 de junio de 1929, 16 de julio de 1930 .

118 El Adelanto, 24 de noviembre de 1908; 8 de mayo de 1928. 
frecuentes de estos eventos vuelven a ser la mujer de Juan De- Bernardi y sus dos hijas mayores ${ }^{119}$.

\section{LA DISPERSIÓN DE LA FAMILIA, EL FIN DE UNA ERA}

Si durante los años 20 hemos encontrado a unos DeBernardi muy activos y presentes en sociedad, el comienzo de la década siguiente supondrá el fin de la unidad familiar por diversos motivos, varios de los cuales ha puesto en conocimiento de esta autora una descendiente directa de José DeBernardi, que ha actuado como informante. Como vimos, ya en 1929 Julia De- Bernardi se había marchado a Asturias para acompañar a su marido médico en su destino, Caravia. En 1931, Lola se marcha a Madrid a "pasar una temporada con sus tíos los Sres. De Castro" ${ }^{120}$. Posiblemente ya no volvería soltera, pues se casaría y viviría allí. 1932 estaría marcado por la tragedia, pues María Romero y una de sus hijas (tal vez Concepción) morían en un accidente de autocar de camino a Béjar, quizás con motivo de las vacaciones de verano $^{121}$.

La falta de documentos digitalizados a partir de este año no nos permite seguir la pista del resto de los miembros de la familia, pero sabemos por nuestra informante que Luis De- Bernardi, el músico más activo del clan, acabaría siendo el director de la orquesta de Mérida, donde actualmente tiene dedicada una calle; Fernando sería comisario general de policía en La Coruña; Ángel moriría en la Guerra Civil; y José fue funcionario en el Instituto Nacional de Previsión. Los que sí quedarían al frente de la tienda familiar salmantina, inmutable a todos estos cambios, serían Juan De- Bernardi, padre e hijo.

\section{EPÍlOGO}

La narración que aquí hemos ofrecido constituye una reconstrucción, parcial y a todas luces incompleta dadas las exigencias de extensión para este artículo, de la historia de una familia instalada en una pequeña ciudad de principios

119 El Adelanto, 29 de octubre de 1907; 27 de enero, 21 de febrero, 16 de marzo y 14 de noviembre de 1908; 23 de marzo de 1915; 3 de septiembre de 1922; 20 y 24 de enero y 26 de noviembre de 1924; 23 de agosto de 1925; 4 de agosto y 6 de septiembre de 1927; 6 de septiembre de 1928 .

120 El Adelanto, 8 de noviembre de 1931.

121 La Gaceta, 8 de agosto de 1932. De este suceso también nos da noticias José María Hernández Pérez en su artículo "La familia Bernardi: organeros en Salamanca" (La Gaceta de Salamanca, 17 de noviembre de 2013), añadiendo que además resultaron heridos otros dos miembros de esta familia. del siglo XX, y de cómo se hicieron un lugar en la alta sociedad de la misma desde su posición de empresarios y músicos. A pesar del aparente carácter local del estudio, debe ser entendido como la representación de un modelo de familia de la burguesía media de provincias dedicada al comercio musical y de su implicación en el desarrollo cultural de la ciudad, concretamente en el ámbito musical.

Hemos visto cómo la dedicación de Juan De- Bernardi al negocio musical le granjeó una posición privilegiada en lo tocante a la participación en actividades concertísticas a través de organizaciones como hermandades o asociaciones de comerciantes. La apertura de un negocio que en un principio se dedicó a la organería en plena reforma del Motu Proprio, haciendo que luego derivara hacia productos más adaptados a los tiempos modernos como la venta de partituras, rollos de pianola, discos y gramófonos, muestra a un empresario de su tiempo, activo y atento a las necesidades de su mercado.

Se abren líneas de estudio a futuro en lo que a esta familia respecta, principalmente relacionadas con Juan DeBernardi (padre), su estilo como constructor de órganos y sus procedimientos de restauración e intervención en órganos, a través de un estudio comparativo de los instrumentos en los que intervino y su morfología antes y después de sus reformas. Pero también con su hijo Luis, su actividad musical una vez se marchó de Salamanca para irse a Mérida y su labor como profesor de música.

Ha resultado ilustrativo observar las costumbres de la familia, sobre todo las relativas a su rutina cultural, principalmente a través de unos hijos educados en colegios de alumnado selecto como eran los Salesianos, las Jesuitinas o las Siervas de San José. Se evidencia una diferencia de trato en los hijos de esta familia, en el que los niños recibían su educación musical no sólo a través de las clases particulares con el maestro de capilla de la catedral, sino también participando en compañías infantiles de zarzuela o en la tuna escolar, para más tarde examinarse en el Conservatorio de Madrid; mientras que las niñas tomaban parte en recitales de poesía o concursos de labores.

Una vez dejaban de ser infantes, sus roles eran también diferentes. Ellos se convertían en sujetos activos de la sociedad introduciéndose en el mundo profesional musical, empresarial en el caso de Juan (hijo) e interpretativo en el de Luis. Su proyección como músicos incluía actuaciones en lugares emblemáticos de la vida musical local, como el Casino, el Pasaje, los teatros Liceo y Bretón... Sin embargo, ellas devenían en objetos pasivos, frecuentando bailes, thé dansant y reuniones de confianza hasta que se casaban. Resulta llamativo que en una familia en la que la música era el modus vivendi no hayamos encontrado proyección en la prensa de actividades musicales de las hijas, dada la cos- 
tumbre en familias burguesas de educar a las mujeres en la música (tanto si era una formación de adorno como si se enfocaba a una dedicación profesional). Si Luis De- Bernardi tuvo alumnas que iban a examinarse al Conservatorio de Madrid, no tenemos noticas similares de que sus hermanas realizaran estudios musicales (oficiales o privados), o de cualquier otra índole.

En cualquier caso, toda la familia en su conjunto se dejaba ver en los "sospechosos habituales" de la vida musical de Salamanca, como los conciertos regulares de los abonos de temporada del Bretón o el Liceo; los bailes de festividades especiales como el Carnaval, Navidad o época estival; o galas de beneficencia en las que colaborar. Queda de este modo retratada la foto de una familia numerosa, moderna en algunos aspectos y conservadora en otros, musical y emprendedora, y coherente con su tiempo y lugar.

\section{BIBLIOGRAFÍA}

Álvarez García, Francisco José, La actividad musical en Salamanca a través de la prensa local. 1900-1910, Salamanca, Ediciones Universidad de Salamanca, Colección Vítor, 2009.

Aviñoa, Xosé, "Los congresos del Motu Proprio (19071928). Repercusión e influencias", Revista de Musicología, 27-1 (Madrid, 2004): 381-400.

Clares Clares, $\mathbf{M}^{\mathrm{a}}$ Esperanza, "Compañías de zarzuela infantiles en Murcia durante la segunda mitad del siglo XIX". Comunicación presentada durante el IX Congreso Nacional de la Sociedad Española de Musicología. Resumen de la comunicación en http://www. sedem.es/upload/web/parrafos/00103/docs/Programa\%20ABSTRACTS\%20Y\%20CV\%20CONGRESO\%20SEdeM\%20version\%20Web.pdf, p. 75.

Gallego, Antonio, "Aspectos sociológicos de la música en la España del siglo XIX”, Revista de Musicología, 14, 1-2 (Madrid, 1991): 13-32.

García Martín, Judith Helvia, "El órgano Amezua de la Iglesia Parroquial de la Purísima Concepción de Salamanca: fuentes para su historia", Nassarre. Revista Aragonesa de Musicología, 31, (Zaragoza, 2015): 149-184.
García Martín, Judith Helvia, "La investigación musicológica de fuentes para la restauración de instrumentos musicales: un caso de recuperación de órgano romántico", La Albolafia. Revista de Humanidades y Cultura, 9 (Madrid, 2016): 31-52.

García Martínez, José María, Del fox-trot al jazz flamenco. El jazz en España. 1919-1996, Madrid, Alianza Editorial, 1996.

Gejo Santos, Isabel, Tradición y modernidad. Dos décadas de música en Salamanca 1940- 1960. Salamanca, Ediciones Universidad de Salamanca, Colección Vítor, 2015.

Pedrell, Felipe, “Orquestadeón”, Diccionario técnico de la música, Valladolid, Maxtor, 2009 (facs. 2a ed. 1897).

Ramos Rubio, José Antonio "Los Bernardi, familia de organeros en Cuacos de Yuste (Extremadura)", Temas de estética y arte, 20 (Sevilla, 2006): 223-229.

Ramos Rubio, José Antonio; Gutiérrez Marcos, Rosario. "Los órganos de Pasarón de la Vera, Losar de la Vera y de Peraleda de la Mata, restaurados por el maestro Nicolás Bernardi e hijos", Temas de estética y arte, 24 (Sevilla, 2010): 363-382.

Randel, Don (ed.), Diccionario Harvard de la Música, Madrid, Alianza Editorial S. A., 1999.

Saura Buil, Joaquín, Diccionario Técnico- Histórico del órgano en España, Barcelona, CSIC, 2001.

\section{FUENTES}

El Adelanto (Todos los números disponibles entre 19021932). Biblioteca Virtual de Prensa Histórica. http://prensahistorica.mcu.es/es/consulta/registro. cmd? $\mathrm{id}=9500$

El Lábaro (Todos los números disponibles entre 1902-1910). Biblioteca Virtual de Prensa Histórica. http://prensahistorica.mcu.es/es/consulta/registro.cmd?id=7188

Entrevista realizada a Pilar De-Bernardi. 2 de febrero de 2017.

Fotografías cedidas por Pilar De-Bernardi a la autora. 2 de febrero de 2017.

Libro de Régimen, fol. 6v. Archivo Parroquial de la Purísima Concepción, Salamanca.

Recibido: 11.04 .2017

Aceptado: 03.09.2017 